Symposium on Recent Advances in Tuberculin and BCG, held at the Institute of Diseases the Chest, London, S.W.3, on January 7, 1963 .

\title{
CELLULAR ASPECTS OF THE TUBERCULIN REACTION
}

\author{
J. L. TURK, M.D. \\ Department of Immunology, Institute of Dermatology, St. Fohn's Hospital for Diseases of the Skin, \\ Homerton Grove, London, E.9
}

THE inflammatory cell population in the tuberculin reaction is mainly of the mononuclear cell type. The number of these cells reaches a peak at about the same time, 24 to 48 hours, as the erythema component of the reaction. The delayed hypersensitivity reaction has been thought to be related to the interaction of the antigen with these mononuclear cells.

Since the demonstration by Landsteiner and Chase (1942) and Chase (1945) that both contact sensitivity to simple haptens and tuberculin hypersensitivity could be transferred passively by predominantly mononuclear cell suspensions, from guinea-pig to guinea-pig, there has been considerable speculation as to the mechanism of this interaction. Cell suspensions that will passively transfer tuberculin sensitivity in the guinea-pig are derived from lymph nodes, the spleen, peripheral blood and peritoneal exudates induced by the intraperitoneal injection of oil, which produces a prédominantly mononuclear cell exudate. These cells may produce generalized sensitivity if given by intravenous or intraperitoneal routes. The intradermal route in the guinea-pig gives local sensitization only (Metaxas and Metaxas Bühler, 1948).

Investigation of the passive transfer of tuberculin sensitivity with cells labelled with radioactive isotopes offers the possibility of determining the fate of such passively transferred mononuclear cells. In the first place experiments of this type can demonstrate if the arrival of donor cells in the passively transferred tuberculin reaction is specific to the reaction, and in this case it is important to see whether such cells can also take part in a delayed hypersensitivity reaction to an antigen different from that with which the donor had been specifically sensitized.

Specificity in the delayed type hypersensitivity lesion can be of two kinds. The arrival of donor mononuclear cells may be specific but only in the sense that they arrive as part of a specific response on the part of the recipient to the introduction any antigen to which it has become sensitive. 每 this sense the donor cells will be reacting in similar manner to the recipient's own cells However, the arrival of donor mononuclear cels may be specific in a particular way. Many more cells may arrive at the site of introduction of a antigen, to which the donor is sensitive, than of or to which the recipient is sensitive but the donor is not. It is important that comparison be made between two reactions of a similar physio-panheo logical nature such as two delayed type hyse sensitivity reactions. Comparison of two re tions with the same gross histological appearance but with different dynamic features can give 공 confusing result.

During the past three years a number of laborå tories have reported the presence of donor mono nuclear cells labelled with ${ }^{3} \mathrm{H}$-thymidine i⿱⺈ passively transferred tuberculin reactions at their peak of development (Najarian and Feldman I96r; Hamilton and Chase, r962; Turk, I962 Kay and Rieke, 1963; McCluskey, Benacerraf and McCluskey, 1963). Najarian and Feldmaz. (I96I) at the same time found that non-sensitized. labelled cells did not accumulate in sites of ing flammation induced by tuberculin nor die sensitized labelled cells appear in infiltrates ino duced by the injection of coccidioidin in non sensitive animals. Hamilton and Chase (1962) found no notable increase in the number of labelled cells at the skin test site over the distribug tion in other organs. The initial finding of Najarian and Feldman (196r) that there was relative failure of labelled cells to accumulate in non-specific inflammatory reaction was confirmeg by Kay and Rieke (1963) comparing the arrivi of cells from a tuberculin-sensitive donor at the passive tuberculin lesion, 24 hours after skin testing, with the arrival of cells at a non-specifio inflammatory lesion to histoplasmin, an antige to which the recipient had not been previousl 


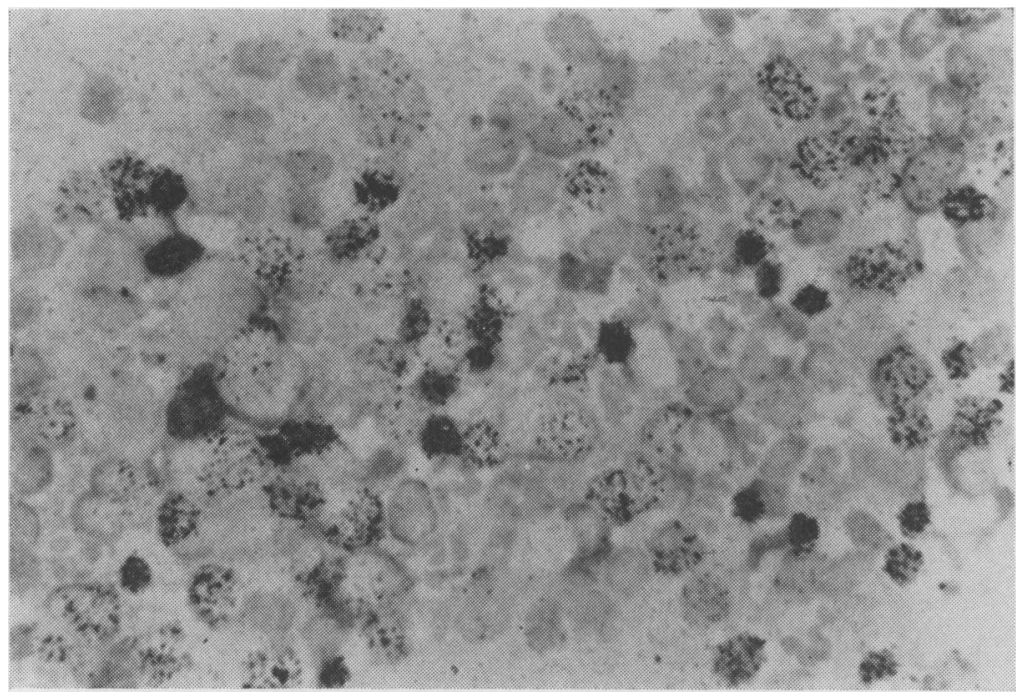

Fig. 1.-Autoradiograph of an imprint of the spleen of a donor guinea $\mathrm{p}: \mathrm{g}$ (tuberculin sensitive). $40 \%$ of small lymphocytes labelled with ${ }^{3} \mathrm{H}$ thymidine.

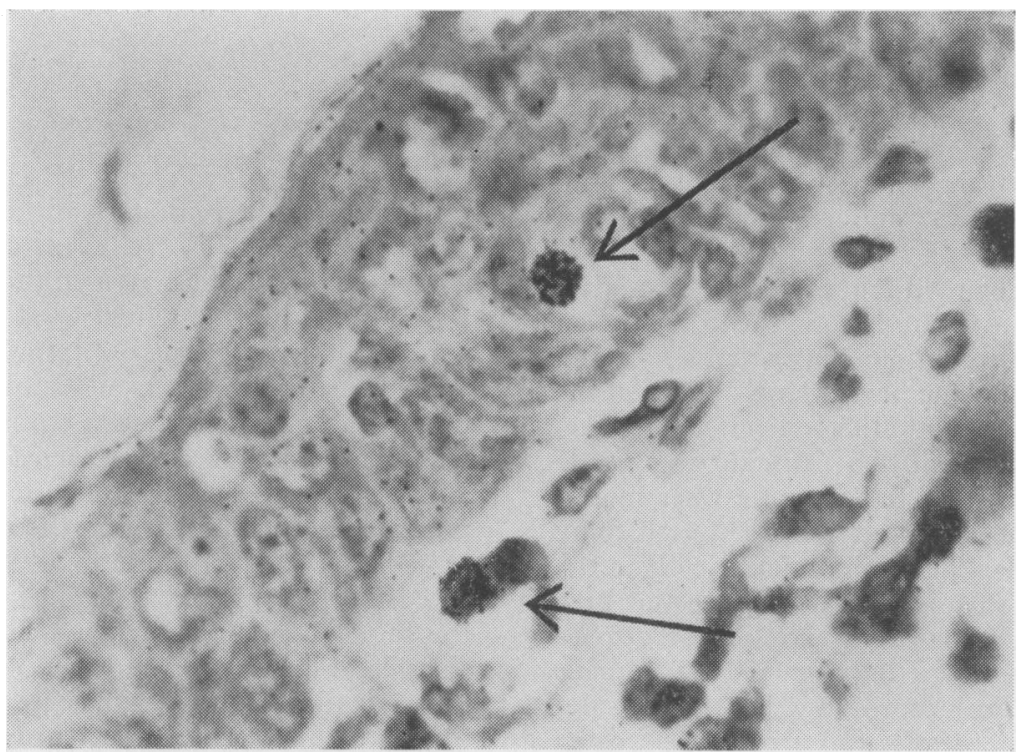

Fig. 2. - ${ }^{3} \mathrm{H}$-labelled lymphocytes in passively transferred tuberculin lesion.

sensitized. However, they emphasize that such a specific accumulation is only apparent if the animal is tested within one hour after passive sensitization when the proportion of circulation labelled cells is high, and that if the animal is tested 24 hours after passive transfer no specific accumulation can be demonstrated despite the fact that the reactions are of the same intensity. They concluded that the number of isotopically labelled cells that appear in a transferred tuberculin reaction depends upon the number available to be attracted to the site of the skin test. Transfused donor cells were not always attracted specifically to the site of the tuberculin test, nor were they required in large numbers at the site for a positive skin resction.

In our experiments (Turk, 1962; Turk and Oort, 1963) we examined the arrival of labelled 
TABLE I

Arrival of ${ }^{3}$ H-Thymidine-labelled Donor Cells at Site of Passively Transferred Tuberculin L.esion, 24 Hours After Skin Test

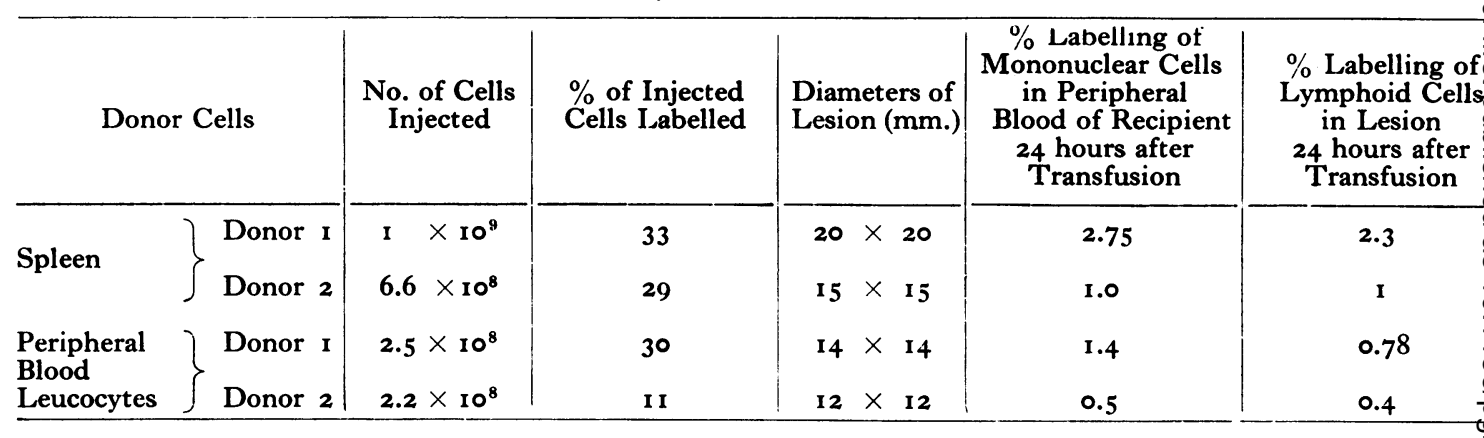

donor cells in the passively transferred tuberculin lesion both in the tuberculin lesion at the height of the reaction ( 24 hours) and during the early stages of the development of the lesion-between four and six hours, and 12 hours after skin testing.

\section{4-Hour Lesion}

Spleen cells and peripheral blood leucocytes, labelled with ${ }^{3} \mathrm{H}$-thymidine, from tuberculinsensitized donors were transfused to normal recipients, which were skin tested with $40 \mu \mathrm{g}$. PPD immediately after transfusion. Twenty-four hours later the lesion was removed for histological examination and smears were made from preparations of peripheral blood leucocytes. Autoradiographs were then prepared from each. Labelled cells were found throughout the sections not only in the exudate round the blood vessels between the musculus carnosus and the dermis, but also throughout the dermis. An estimate was made of the proportion of labelled cells to other mononuclear cells in the skin, and this was found to be similar to that of labelled mononuclear cells in the peripheral blood (Table I). Moreover the proportion of labelled cells in the skin appeared to be related more to the total number of labelled cells injected than to the size of the lesion that developed. In the largest lesion seen there was an apparent grouping of labelled cells, giving occasional fields where the proportion of labelled cells might be four times that in the peripheral blood, but the overall proportion of labelled cells throughout the sections was not greatly different from that in the peripheral blood.

To ascertain whether the total number of labelled cells arriving in a passively induced tuberculin lesion would be greater than those arriving in a delayed-type lesion of different specificity, cells labelled with ${ }^{51} \mathrm{Cr}$ and ${ }^{32} \mathrm{P}$ were used. In these experiments it was not known what percentage of cells in a labelled cell population actually carried the label. For the purpose of comparison it was presumed that $100 \%$ of the cells were labelled, though there was no evidenge for this. The term 'cell equivalent' was therefore introduced and the following expression used to indicate the number of 'cell equivalentsi' present in a particular tissue:

Number of cell equivalents $=$ number of counts $/ 1,000$ seconds in lesion $\times$ number of cells injected Number of counts/1,000 seconds injected

The arrival of ${ }^{51} \mathrm{Cr}$ and ${ }^{32} \mathrm{P}$ labelled cells tuberculin-sensitive donors at the tuberculin \$Fintest site, defined as the area of erythema, we compared with their arrival at the sites of delaye type lesions due to human $\gamma$-globulin (HGG) animals actively sensitized with antigen-antibo\&y precipitates in water-in-oil emulsion. In all t $\overrightarrow{B e}$ lesions the radioactivity was equivalent to between $0.6 \times 10^{5}$ and $8 \times 10^{5}$ cells (Turk, 1962), the amount of radioactivity in both cases being proportional to the degree of erythema. The number of cell equivalents in tuberculin lesions was two to three-fold greater than that in HGG lesions with the same areas of erythema. This difference was thought to be due to the HGG lesions being mole diffuse and less cellular than the tuberculin lesiog. The amount of radioactivity present in the lesions was equivalent to between 0.05 and $0.7 \%$ of the cells injected.

Similar conclusions to these have been recent presented by McCluskey, Benacerraf and McCluskey (1963) who transferred delayed sensis tivity with ${ }^{3} \mathrm{H}$ labelled lymph node cells in two non-cross reacting sensitivity systems. The systems used were delayed sensitivity to picfl 1 chloride, p.chlor. benzoyl chloride and diphtheriag toxoid. Donors sensitized to one of the antigenss received ${ }^{3} \mathrm{H}$-thymidine, whereas donors sensitized to one of the other systems supplied unlabelled cells. Delayed sensitivity reactions elicited 
TABIE 2

Arrival Of ${ }^{3}$ H-Thymidine Labelled Donor Cells at Site of Passively Transferred Tuberculin Lesion, 4, 6 AND 12 Hours After SkIN Test

\begin{tabular}{|c|c|c|c|c|}
\hline \multirow[b]{2}{*}{ Time } & \multirow{2}{*}{$\begin{array}{l}\% \text { Donor } \\
\text { Cells } \\
\text { Labelled }\end{array}$} & \multicolumn{3}{|c|}{ Mononuclears } \\
\hline & & $\begin{array}{c}\text { Peripheral } \\
\text { Blood }\end{array}$ & $\begin{array}{c}\text { Tuberculin } \\
\text { Lesion }\end{array}$ & $\begin{array}{l}\text { HGG Con- } \\
\text { trol Lesion }\end{array}$ \\
\hline $\begin{array}{l}4 \text { hrs. } \\
6 \text { hrs. } \\
12 \text { hrs. }\end{array}$ & $\begin{array}{l}24 \\
20 \\
25\end{array}$ & $\begin{array}{r}8 \\
10 \\
10\end{array}$ & $\begin{array}{l}0.1-3.0 \\
1.2-1.5 \\
4.0-8.1\end{array}$ & $\begin{array}{l}0.7-1.4 \\
0-1.2 \\
8.4-14.8\end{array}$ \\
\hline
\end{tabular}

each of the antigens at separate sites in these recipients were found to contain comparable numbers of labelled cells.

\section{Early Stages of Development of the Lesion}

The findings in the passive tuberculin lesion 24 hours after skin testing suggested that there is no specific localization of the transfused cells in the fully developed lesion. We still thought it possible that we might detect some specific localization at an earlier stage, using cells labelled with ${ }^{3} \mathrm{H}$-thymidine.

No significant difference could be found between the arrival of labelled cells from a tuberculin-sensitive donor in the passively transferred specific tuberculin lesion and the actively induced delayed-type lesion to HGG four and six hours after skin test. In the lesions examined 12 hours after skin test there was actually a greater number of labelled cells in the HGG control lesion than in the specific PPD lesion (Table 2).

In the interpretation of the difference in delayed reactions to different antigens one must take account of the relative part played by proliferation of local mononuclear cells in the development of the reaction (Kosunen, Tihen and Waksman, 1962). A greater local proliferation of mononuclear cells in the tuberculin than in the HGG lesion could give an explanation for any difference between the proportion of labelled mononuclear cells in these two lesions. It is also probable that the accumulation of local mononuclear cells (e.g. tissue histiocytes) occurs as one of the earliest stages in the reaction. This could account for the very low proportion of mononuclear cells which are labelled at four and six hours compared with the proportion labelled at 12 and 24 hours.

When the histological reactions in the skin of normal and sensitized guinea pigs to the intradermal injection of PPD and HGG were compared, up to 12 hours they showed no specific features that could be associated with the delayed hypersensitive state. After 12 hours there was a small but definite increase in mononuclear cells and granulocytes, in sensitive as compared with normal animals.

It would therefore appear that the arrival of donor cells in the area of antigen injection four to six hours after skin test was a non-specific phenomenon in response to the intradermal injection of any antigen; the reason for this is not known. However, once the cells are able to react with antigen a 'chain reaction' is started with the typical tuberculin reaction as the end product. Though our data have failed to demonstrate any specific attraction of donor cells to the site of antigen injection, this does not mean that the tuberculin reaction is not due to the reaction of the sensitized cell with the antigen at the injection site, though it is probable that they are not required in large numbers for a positive reaction to develop.

There are a number of possible hypotheses about the way in which a delayed-type lesion could develop. In one category are those which postulate that the 'active cell' arrives in the lesion. This is currently the most widely held hypothesis. The 'active cell' may carry an antibody-like activity, which it has acquired passively, on its surface and thereby be able to react with locally injected antigen, or an ' active cell' may arrive in the lesion and there produce an antibody-like activity locally. This may remain attached to the cell or be released from it. The reaction with antigen may occur at the surface of the cell or at a distance.

The second category of hypotheses presumes that the ' active cell' tends to settle in recipient lymphoid tissue. The cell may then pass on information to the recipient's own lymphoid cellsa modified form of active sensitization. Karush and Eisen (1962) have, however, put forward the hypothesis that the phenomena associated with delayed hypersensitivity can be explained by the continuous secretion of small amounts of high affinity humoral antibody. If this hypothesis is correct passive transfer would be by means of antibody-secreting cells settling in the recipient's lymphoid tissue and secreting small amounts of the high-affinity antibody, postulated by Karush and Eisen (1962), into the circulation.

\section{REFERENCES}

Chase, M. W. (1945): The Cellular Transfer of Cutaneous Hypersensitivity to Tuberculin, Proc. Soc. exp. Biol. (N. Y.), 59, 134.

Hamilton, L. D., and Chase, M. W. (1962): Labeled Cells in the Transfer of Delayed Hypersensitivity, Fed. Proc., 2I, 40.

References continued on page 73 . 
the largest zones (and one other patient who failed to develop induration) were suffering from active tuberculosis. Hence only two non-tuberculous patients amongst 136 negative reactors developed erythema more than $10 \mathrm{~mm}$. in diameter in the absence of induration. This hardly supports the view that the development of erythema in response to tuberculin is entirely non-specific. In some ways more interesting is the development of lone erythema in patients with active tuberculosis. A number of workers have now described the failure of some tuberculous patients to develop conventional positive reactions on testing with large doses of tuberculin, even though no recognized cause of reduced sensitivity could be demonstrated. Amongst those encountered in this series, although induration did not develop, erythema always occurred. I suggest that this reaction represents an extreme form of the tuberculous response in which, while erythema is preserved, induration has become so attenuated as to be unrecognized.

Fig. I and Table $\mathrm{I}$ are taken from Brit. F. Dis. Chest (1959), 53, 181 , and Fig. 2 from Brit. F. Dis. Chest (1956), 50, 159, with permission of the Editor.

\section{REFERENCES}

O'Grady, F. (1956): Mantoux Reaction Patterns in Active and Arrested Tuberculosis, Brit. F. Tuberc., 50, 159. WolfF-Eisner, A., and Teichmann, F. (1908): Die Prognostische Bedeutung der Conjunctivalen und Cutanen Tuberculinreaktion, Berl. klin. Wschr, 45, 65 .

Continued from page 69.

\section{REFERENCES}

KARUSH, F., and EISEN, H. N. (1962): A Theory of Delayed Hypersensitivity, Science, 136, 1032.

KAY, J., and RiEke, W. O. (1963): Tuberculin Hypersensitivity: Studies with Radioactive Antigen and Mononuclear Cells, Science, I39, 487.

Kosunen, T. U., Tinen, W. S., and Waksman, B. H. (r962): Use of Radioautography to Show Cell Proliferation in Delayed Hypersensitivity Reactions, Fed. Proc., 21, 274.

LANDsteiner, K., and Chase, M. W. (I942): Experimental Transfer of Cutaneous Sensitivity to Simple Compounds, Proc. Soc. exp. Biol. (N.Y.), 49, 688 .

McCluskey, R. T., Benacerraf, B., and McCluskey, J. W. (1963): Studies on the Specificity of the Cellular Infiltrate in Delayed Hypersensitivity Reactions, $\mathcal{F}$. Immunol., 90, 466.

Metaxas, M. N., and Metaxas Buhler, M. (1948): Passive Transfer of Local Cutaneous Hypersensitivity to Tuberculin, Proc. Soc. exp. Biol. (N.Y.), 69, 163 .

Najarian, J. S., and Feldman, J. D. (I96I): Passive Transfer of Tuberculin Sensitivity by Tritiated Thymidine Labeled Cells, F. exp. Med., II4, 779 .

Turk, J. L. (1962): The Passive Transfer of Delayed Hypersensitivity in Guinea-pigs by the Transfusion of Isotopicallylabelled Lymphoid Cells, Immunology, $5,478$.

, and OORT, J. (1963): A Histological Study of the Early Stages of the Development of the Tuberculin Reaction After the Passive Transfer of Cells Labelled with $\left({ }^{3} \mathrm{H}\right)$-thymidine, Ibid., 6, 140. 